\title{
O lúdico em tempos de (des)esperanças
}

Jonathan Aguiar ${ }^{1}$

Submetido em: 07/09/2020

Aprovado em: 06/10/2020

DOI: 10.5965/23580925242020115

1 Doutorando em Educação. Universidade Federal do Rio de Janeiro (UFRJ).

E-mail: escritorjonathan@gmail.com 


\section{RESUMO}

O presente texto baseia-se em uma roda de conversa, intitulada: "Imaginação e Lúdico", realizada no I Ciclo de Conversa da Brinquedoteca Pedagoginga, da Universidade Federal Rural do Rio de Janeiro (UFRRJ) de modo virtual. Desse modo, apresenta-se um breve relato de experiência que busca contribuir para construção de conhecimento e ampliação do debate sobre a importância do brincar e das atividades lúdicas-criadoras na decorrência de um período de pandemia e pós-pandemia. Após a reflexão das ideias de Lauand (2006), Vigotski (2014) sobre lúdico e criatividade, concluímos que diante do brincar abrimos novas janelas para se aprender a conviver, acolher o outro e viver saudavelmente entre o riso e o choro. O lúdico significa ação e sua dimensão torna potência quando recriamos, elaboramos novos mundos a nossa volta recuperando as experiências que vivemos.

Palavras-chave: criatividade, brincar, lúdico

\section{ABSTRACT}

This text is based on a conversation circle, entitled: "Imagination and Playfulness", held in the 1st Conversation Cycle of the Pedagoginga Toy Library, of the Universidade Federal Rural do Rio de Janeiro (UFRRJ) in a virtual way. Thus, a brief experience report is presented that seeks to contribute to building knowledge and expanding the debate on the importance of playing and recreational-creative activities as a result of a pandemic and post-pandemic period. However, after reflecting on the ideas of Lauand (2006), Vigotski (2014) on playfulness and creativity, we conclude that when playing, we open new windows to learn to live together, welcome others and live healthily between laughter and crying. The playful means action and its dimension becomes power when 
we recreate, we create new worlds around us recovering the experiences we live.

Keywords: creativity, play, playfulness.

\section{ALGUNS OLHARES PARA INIICIO DE CON- VERSA}

O presente texto baseia-se em uma roda de conversa intitulada: "Imaginação e Lúdico", realizada no I Ciclo de Conversa da Brinquedoteca Pedagoginga², da Universidade Federal Rural do Rio de Janeiro (UFRRJ) de modo virtual.

Participar de uma roda de conversar de modo virtual tem permitido refletir sobre os espaços de formação inicial e continuada de educadores, professores e pesquisadores, de quanto as ferramentas tecnológicas também tem permitido aproximações, diálogos, reflexões e aproximações entre o campo da educação, arte e infâncias. Por outro lado, existem também angústias e incertezas por aqueles que sentem na pele os percalços de saber que a única forma de se manter conectado com o mundo, com as instituições de ensino e outros contextos sociais acontece somente via tela do celular, computador ou tablet, devido às altas taxas de transmissão e contágio do covid-19.

Escolas fechadas, economia paralisada, saúde em caos. Os problemas referentes à educação e à saúde ficaram acentuados com o advento dessa guerra sanitária, apesar de existirem antes de qualquer pandemia mundial que assola os territórios brasi-

2 A proposta da Brinquedoteca Pedagoginga tem como objetivo contribuir com a formação de estudantes dos cursos de Pedagogia e outras licenciaturas oferecendo um espaço formativo dentro da Universidade Federal Rural do Rio de Janeiro (UFRRJ) em parceria com a Universidade do Estado do Rio de Janeiro (UERJ) e a Universidade Federal do Rio de Janeiro (UFRJ). É por sua natureza, um projeto multi, inter e transdisciplinar que tem como tripé a pesquisa, o ensino e a extensão. Nesse sentido, a Brinquedoteca Pedagoginga é uma proposta que reúne atividades extensionistas na elaboração de uma linha de comunicação plural que busca outras epistemologias do ser brincante. 
leiros (SANCHES; PARDIM, 2020).

Realmente, estamos em um grande mar, onde cada um ocupa um lugar diferente dentro de suas canoas, iates, botes, bóias e até mesmo pequenos pedaços de madeiras que sustentam alguns nas superfícies e outros acabam se afogando. Essa história é a realidade que enfrentamos no Brasil e no contexto mundial, um período de difusão do corona vírus, denominado cientificamente segundo a Organização Mundial de Saúde (OMS) como covid-19 (G1-GLOBO, 2020). Em fevereiro, nenhum caso confirmado no Brasil, segundo a notícia publicada no portal G1 da Globo, no entanto, existiam 7 (sete) casos suspeitos, enquanto na Itália passava de mil mortes.

Com um curto intervalo de tempo, o Brasil confirma o primeiro caso, no dia 26 de fevereiro de 2020 (FOLHA DE SÃO PAULO, 2020). A partir daí, no mês de junho, o Brasil ultrapassa a Itália chegando a ser o $3^{\circ}$ país com maior número de mortos (VALOR, 2020). Com isso, muda-se a rotina de milhares de pessoas, os cuidados de higiene pessoal, a organização familiar e, sobretudo, o comportamento humano. Desse modo, surgem as seguintes indagações: Com a pandemia, o que modificou na vida humana? O distanciamento social trouxe questões universais que precisam ser discutidas em sociedade? De que maneira as especificidades locais, territoriais são apresentadas em um período de isolamento devido ao covid-19?

As perguntas destacadas acima tem nos movido para múltiplas realidades subjetivas e coletivas em variados espaços-tempos que estamos situados. Paralelamente, segue nesse texto um breve relato de experiência que busca contribuir para construção de conhecimento e ampliação do debate sobre a importância do brincar e das atividades lúdicas-criadoras na decorrência de um período de pandemia e pós-pandemia, principalmente no contexto de favela.

Portanto, assumimos nessa produção o quanto o lúdico é fundamental no desenvolvimento e na aprendizagem humana. Assim, nos aproximamos dos estudos de Lauand (2006), Vigotski (2014), Aguiar (2019) por entenderem que o lúdico é mais do que 
apropriação de jogos e brincadeiras, mas sim todo um processo de reconhecimento de simbolização, da fantasia e apropriação da arte de brincar, aprender com a vida e a espécie humana, por sermos seres brincantes.

Cabe dizer que esse relato foram as reflexões do autor deste texto como participante (palestrante) da roda de conversa com educadores no $1^{\circ}$ semestre de 2020.

\section{DA MINHA JANELA: EXPERIÊNCIAS LÚDICAS- -CRIADORAS QUE PROPICIAM A IMAGINA- ÇÃO}

O livro “Da minha janela” escrito por Otávio Júnior e ilustrado por Vanina Starkoff, publicado pela Editora Companhia das Letrinhas, nos provoca a pensar que nenhuma janela do mundo tem a mesma paisagem. As páginas ilustradas por Vanina e as palavras de Otávio, nos contam o que é possível enxergar de sua janela, localizada na favela, despertando o que cada um vê de sua janela (OTÁVIO JúNIOR, 2019). Com a utilização desta obra, foi realizado o momento de contação de histórias no sentido de ampliar as reflexões e sensibilizar os participantes a reconhecerem um mundo para além de suas respectivas janelas. Desse modo, a pergunta mobilizadora para a conversa foi: "O que você enxerga da sua janela?".

É importante descrever que diante dessa problematização na interface com o período pandêmico, o autor desse texto ao abrir a sua janela depara-se com crianças brincando, criando, reelaborando momentos lúdicos com caixa de papelão e o jogar futebol, assim expõe também outras situações no artigo de opinião publicado no jornal de ampla circulação na cidade do Rio de Janeiro "Em defesa do Brincar".

[...] confesso que por viver dentro de uma favela ainda encontro crianças nas ruas, vielas e becos. Tanto que escutei de minha janela, crianças gritanto: "Gooooool! Vai, vai". Ao abrir o portão deparo-me com a garotada jogando futebol. Assim me pergunto: 


\begin{abstract}
"Por que elas não estão dentro de casa?", insatisfeito com o ocorrido me dirijo ao adulto que assistia. O mesmo fala: "Dentro de casa não tem espaço, melhor aqui fora, ué". Explico com muito afeto o momento que estamos vivendo no país e este diz "deixam eles brincar" (AGUIAR, 2020, p. 14).
\end{abstract}

Ainda sobre as experiências do autor supracitado, o mesmo destaca o relato de uma mãe ao dizer "Eu não sei brincar com meu filho". Como desdobramento cria-se a "Bússola do ser Brincante" (Figura 1) organizado por Aguiar e Santos (2020), com a participação e autoria de diversos pesquisadores, professores e estudantes da graduação com propósito de ampliar a discussão sobre a importância do brincar com crianças e também indicar alguns direcionamentos para que a expressão da arte, do movimento e a essência lúdica passe a existir como potência nos espaços familiares, neste caso, dentro de casa com aqueles que podem permanecer nos seus lares em isolamento devido a covid-19.

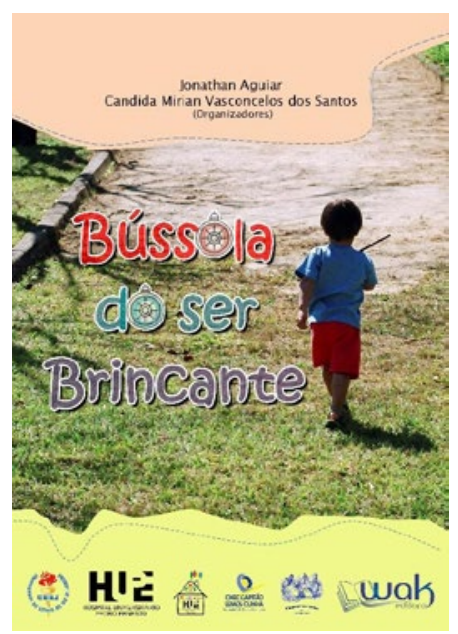

Figura 1: Bússola do Ser Brincante

Fonte: https://bussoladoserbrinca.wixsite.com/bussolabrincante 
Desse modo, indaga-se: o que é lúdico? O que é criatividade? Existem experiências lúdicas-criativas coexistindo nesse momento de pandemia? De certo modo, o brincar permanece na experiência aqui relatada e seus desdobramentos a partir de materiais que foram assim produzidos a fim de constituir um espaço brincante com crianças e adultos.

Buscando responder a primeira questão: o que é lúdico? Nos aproximamos dos estudos Lauand (2006) ao dizer que o brincar encontra-se na razão mais profunda do mistério. O Professor Titular Sênior da Faculdade de Educação da Universidade de São Paulo (USP) e pesquisador que tem se dedicado às investigações no campo da filosofia, ética, religião e arte, situa o lúdico no brincar no pensamento do filósofo Tomás de Aquino. Ao escrever o artigo "Deus Ludens - o lúdico na pedagogia medieval e no pensamento de Aquino" esclarece que o lúdico demarca uma passagem do tempo, principalmente quando busca-se compreender as maneiras que indivíduos brincam, cultivam a piada e o riso. Logo, o lúdico significa a expressão cultural e sensível da convivência humana.

Lauand (2006) refere-se ao lúdico nos povos da Idade Média, cujo seu caráter é amplo, principalmente ao citar a obra do historiador Johan Huizinga, conhecida como "Homo Ludens" por entendê-lo como um aspecto cultural e reconhecendo que este é intrínseco à vida humana, tanto em adultos como em crianças.

Jean Lauand afirma com base nas reflexões de Tomás de Aquino que o termo "lúdico" advém das palavras ludus e iocus, e concebe-as como sinônimos.

Em latim, a palavra iocus tende a ser mais empregada para brincadeiras verbais: piadas, enigmas etc. loca monachorum, por exemplo, é o título que designa as coleções de charadas, enigmas e brincadeiras verbais dos monges nos mosteiros medievais. A forma inglesa joke, conserva essa ênfase no verbal. Já ludus - da qual se originaram as nossas: aludir, deludir, desiludir, eludir, iludir, ineludível, interlúdio, ludâmbulo, ludibriar, lúdico, prelúdio etc.- refere-se mais ao brincar não verbal: por ação. No entanto, no século XIII iocus e ludus empregam-se frequentemente 
como sinônimas. Assim, por exemplo, diz Tomás: “As palavras ou ações - nas quais se busca só a diversão chamam-se lúdicas ou jocosas", "A diversão acontece por brincadeiras (ludicra) de palavra e de ação (verba et facta)" (II-II, 168, 2, c) (LAUAND, 2006, p. 43).

Logo, atribui-se ao lúdico um universo amplo de significados, no entanto, de acordo com Lauand, assume o lugar da ação de qualquer sujeito. Ao utilizar jogos, brinquedos e brincadeiras, este indivíduo se envolve, interage com esses objetos lúdicos e o brincar assim estabelece. O riso, o humor e o choro podem surgir entre os movimentos brincantes, entre o convidar para brincar e assim citar outras formas elementares de jogar, criar e imaginar tanto na escola como em outros contextos sociais e culturais, isto é lúdico. Quando crianças pequenas, adultos e idosos buscam transgredir regras, infringir normas autoritárias e se veem desafiados a possibilitar outros fazeres pedagógicos, emancipatórios, plurais e transformadores de mudanças, o lúdico também ocupa lugar na vida, no pensar e nas tentativas de constituir um ambiente saudável, plural e mais participativo, onde cada sujeito possa se desenvolver, comentar, analisar e criar outras maneiras de aprender, rompendo com as lógicas tradicionais e mecânicas.

O lúdico é um exercício diário, é um processo de esperança e de desesperançar-se, quando se joga, sujeitos perdem, sujeitos ganham e nesse movimento aprende-se a lidar com as frustrações, com as alegrias e as expectavas que são projetadas em cada arte de jogar entre as regras e os modos de vencer ou se chegar em algum lugar. Por outro lado, o lúdico é um esforço de alimentar sonhos, conquistas, aprendizagens, cooperação, valores, colaboração, assistência, princípios éticos, cidadania, desenvolvimentos e reelaborações. O lúdico pode significar pausa, ritmo, sons, músicas, artes, danças que tocam a alma, o interior e o mundo físico de qualquer pessoa.

$\mathrm{O}$ ato de se divertir também é lúdico, pois o seu propósito é reconectar a vida a outros mundos, realidades, imagens, sons e aprendizagens entre as interações com crianças, adolescentes, jovens, adultos e idosos, onde não se restringe à infância. O lú- 
dico tem lugar em qualquer faixa etária, se crianças brincam, se adultos jogam e idosos dão risadas, os aspectos do lúdico e sua ação são existenciais. Neste sentido, quando Lauand (2006) descreve a origem da palavra Ludus existe por referir-se ao movimento de homens, mulheres, crianças, pretos, favelados, idosos e qualquer outro sujeito humano, que pulsa o viver, o respeitar, o sentir.

Para ampliar um pouco mais esta perspectiva aqui defendida, relacionamos com a visão vigotskiana ao dizer que a criatividade habita em qualquer espécie humana e não está somente ligada a grandes gênios na literatura, da arte e da música. Neste ponto assinalamos o que é criatividade na interface com o conceito de lúdico. Vigotski (2014) explica:

[...] sua essência consiste no fato de o homem reproduzir ou repetir normas de comportamento anteriores criadas e elaboradas, ou relembrar impressões passadas. Quando me lembro da casa onde vivi na minha infância, ou de países distantes que visitei, estou reproduzindo os traços daquelas impressões vividas na infância ou durante as viagens. Do mesmo modo, quando desenho a partir de observações da natureza, escrevo ou faço qualquer coisa segundo um modelo, em todas essas situações reproduzo apenas o que está diante de mim, ou o que foi por mim anteriormente assimilado e elaborado. Em todos esses casos o que há de comum é que a minha atividade não cria nada de novo, limitando-se fundamentalmente a repetir com maior ou menor precisão alguma coisa já existente (VIGOTSKI, 2014, p. 1).

Em sua obra "Imaginação e criatividade na Infância", ressalta que a atividade criadora da humanidade é combinar e criar, em suas palavras ele destaca: "Toda a atividade humana que não se restringe à reprodução de fatos e impressões vividas, mas que cria novas imagens e ações, pertence a essa segunda função criadora ou combinatória" (VIGOTSKI, 2014, p. 3). O mesmo continua que esta atividade faz com que o "homem um ser que se projeta para o futuro, um ser que cria e modifica o seu presente" (VIGOTSKI, 2014, p. 3).

Diante disso, o ato de criar, brincar e ser lúdico nos leva a 
refletir que este refere-se à ação, ao envolvimento, à experiência subjetiva de cada sujeito pensante, reflexivo e prático. Crianças e adultos que brincam, imaginam e criam nesse momento pandêmico tornam o viver rico de aprendizagens, mesmo aquelas que são duras como a morte e a perda, no entanto somente no brincar livra-se das angustias, dos medos e das desesperanças, eis o lúdico.

Isto posto, quando também crianças brincam, adultos se envolvem em suas ações criadoras e imaginativas e o lúdico se manifesta e torna-se real. Até porque o "jogo implica garantir um lugar às ideias, à representação dos objetos, à imaginação, enfim, à construção do conhecimento como uma leitura significativa do mundo" (HEINSIUS, 2020, p. 61).

Portanto, o lúdico abre espaço para conectar-se com a vida, em defesa da vida, exigindo que a própria espécie humana viva momentos onde se possa brincar e imaginar (AGUIAR, 2019). Criar ou direcionar momentos lúdicos é indispensável para aprender a relacionar-se consigo mesmo e com o outro, ampliando o seu mundo, lidando com sua realidade que enxergamos e observamos de nossas janelas e expandimos para outros mundos, outros contextos. Indivíduos que brincam aperfeiçoam seus modos de viver a vida, acreditamos que este pode ser um movimento fundamental para aqueles que nesse momento jogam bola da rua, brincam de boneca na escada e exercitam o imaginar.

\section{ABREM-SE JANELAS: IMAGINAÇÕES E CRIA- ÇÕES}

[...] Mas as pessoas não deveriam chamar aquele local adorável de Avenida. Não tem sentido um nome como este. Deveriam chamá-lo - deixe-me ver - Caminho Branco de Deleites. Não é um ótimo nome imaginário? Quando eu não gosto do nome de algum lugar ou pessoa, sempre imagino um novo, e sempre penso neles dessa forma. (MONTGOMERY, 2019, p. 19). 
Aproveitando as falas de Anne $^{3}$ e todo seu processo criador e imaginário de novos nomes a lugares e pessoas, evidencia que esta menina viveu experiências anteriores significativas, as quais hoje consegue reelaborar outros contextos, outras formas de se expressar e continuar projetando coisas para o futuro. $\mathrm{Na}$ história de Anne, é possível enxergar toda a visão vigotiskiana sobre criatividade e imaginação, apesar deste texto não se preocupar em analisar a história, desdobramentos e narrativas dessa menina, tais discursos nos provocaram algumas ideias nesse texto, que se insere como um relato de experiência do quanto o lúdico habita a vida humana e este permanece em momentos de pandemia e pós-pandemia no fazer de crianças e no pensar entre adultos e pesquisadores.

Nessa perspectiva, questões ressurgem e dão lugar à novos questionamentos a respeito do lúdico: a) Qual é a sua decisão como ser humano na defesa de uma educação que prioriza o brincar, o criar e o imaginar da espécie humana? b) É possível brincar em períodos de isolamento/distanciamento social? c) Com o advento da tecnologia, o uso de celulares e outras ferramentas digitais, como ser lúdico? Concluímos que diante do brincar, abrimos novas janelas para se aprender a conviver, acolher o outro e viver saudavelmente entre o riso e o choro. 0 lúdico significa ação e sua dimensão torna potência quando recriamos, elaboramos novos mundos a nossa volta recuperando as experiências que vivemos. A pandemia vai passar, somente aqueles que brincaram conseguiram resistir aos fracassos, às lágrimas e às desesperanças. Logo, o lúdico é libertador, liberta a dor.

3 Uma jovem órfã no final da década de 1890, que, depois de uma infância abusiva passada em orfanatos e casas de estranhos, é enviada por engano para viver com dois irmãos, uma senhora mais velha e um senhor, seu irmão mais novo, solteiros. Anne Shirley, uma menina falante de 13 anos com uma imaginação brilhante. 


\section{REFERÊNCIAS}

AGUIAR, J. Educação, lúdico e favela: quantos tiros são necessários para aprendizagem? Rio de Janeiro: Wak Editora, 2019.

AGUIAR, J. Em defesa do brincar. Rio de Janeiro: Jornal O Dia, 4 de julho de 2020. Disponível em: https://www.pressreader.com/ brazil/o-dia/20200704/281938840197282. Acesso em: 07 de set. de 2020.

AGUIAR, J.; SANTOS, C. M. V. dos. Bússola do ser brincante. [eletrônico] Rio de Janeiro: UERJ/ Brinquedoteca da HUPE/ Brinquedoteca CNEC-IIha do Governador/ Brinquedoteca BrincArte Estácio Nova Iguaçu/ Wak Editora, 2020. Disponível em: https://bussoladoserbrinca.wixsite.com/bussolabrincante. Acesso em: 07 de set. de 2020.

FOLHA DE SÃO PAULO. Brasil confirma primeiro caso do novo coronavírus. 26/02/2020. Disponível em: <https://www1.folha. uol.com.br/equilibrioesaude/2020/02/brasil-confirma-primeirocaso-do-novo-coronavirus.shtml > Acesso em: 11 de ago. de 2020.

G1-GLOBO. Doença provocada pelo novo coronavírus é batizada de Covid-19 pela OMS. 11/02/2020. Disponível em:<https://g1.globo.com/ciencia-e-saude/noticia/2020/02/11/ oms-da-nome-a-doenca-provocada-pelo-novo-coronaviruscovid-19.ghtml > . Acesso em 11 de ago. de 2020.

LAUAND, J. Deus Ludens: O lúdico na pedagogia medieval e no pensamento de Tomás de Aquino. In: ARANTES, V. M. (org.). Humor e Alegria na Educação. São Paulo: Summus, 2006. p. $31-55$.

MONTGOMERY, L. M. Anne de Green Gables (Livro 1). 4a ed. ES: Pedra Azul Editora, 2019. 
OTÁVIO JÚNIOR. Da minha janela. 1a ed. São Paulo: Companhia das Letrinhas, 2019.

SANCHES, E. M. B. C. C.; PARDIM, R. P. Fechamento das escolas; entre a necessidade do isolamento social e a essencialidade do serviço educacional - como ficam as crianças? In: LIBERARI, F. C. et al. (orgs.). Educação em tempos de pandemia: brincando com um mundo possível. 1a ed. Campinas: Pontes Editores, 2020.

VALOR. Brasil ultrapassa Itália é o $3^{\circ}$ país em número de mortes por covid-19. Disponível em: <https://valor.globo.com/ brasil/noticia/2020/06/04/brasil-ultrapassa-italia-e-o-3o-paisem-numero-de-mortes-por-covid-19.ghtml > Acesso em: 11 de ago. de 2020.

VIGOTSKI, L. S. Imaginação e criatividade na infância. São Paulo: Editora WMF Martins Fontes, 2014. 